\title{
Family Cohesion Is Associated with the Self-Perceived Need for Dental Treatment among Adolescents
}

\author{
Isolda M. L. F. Prata ${ }^{D}{ }^{1}$ Ana Flávia Granville-Garcia ${ }^{(D)}{ }^{1}$ Érick T. B. Neves ${ }^{(D)}{ }^{1}$ \\ Larissa C. M. Lima $\mathbb{D}^{1}{ }^{1}$ Laio C. Dutra $\mathbb{D}^{1}$, Matheus F. Perazzo $\mathbb{D}^{2},{ }^{2}$ Fernanda M. Ferreira $\mathbb{D}^{2}$, \\ and Saul M. Paiva ${ }^{2}{ }^{2}$ \\ ${ }^{1}$ Department of Dentistry, School of Dentistry, State University of Paraíba, Campina Grande 58429-500, Brazil \\ ${ }^{2}$ Department of Paediatric Dentistry, School of Dentistry, Federal University of Minas Gerais, Minas Gerais 31270-901, Brazil
}

Correspondence should be addressed to Ana Flávia Granville-Garcia; anaflaviagg@gmail.com

Received 24 May 2021; Accepted 14 September 2021; Published 29 September 2021

Academic Editor: Gelin Xu

Copyright ( 2021 Isolda M. L. F. Prata et al. This is an open access article distributed under the Creative Commons Attribution License, which permits unrestricted use, distribution, and reproduction in any medium, provided the original work is properly cited.

\begin{abstract}
This study explored the association between family cohesion and self-perceived need for dental treatment among adolescents. A school-based representative cross-sectional study was conducted with 746 students aged 15 to 19 randomly selected from schools in Campina Grande, Brazil. Parents/guardians provided information on sociodemographic data, and students completed questionnaires about the self-perceived need for dental treatment, dental pain, and family cohesion and adaptability (FACES III). Two dentists were trained (kappa >0.80) to diagnosis dental caries using the Nyvad criteria and assess adolescents' level of functional oral health literacy (BREALD-30). Descriptive analysis was performed, followed by nonadjusted and adjusted robust binary logistic regression for complex samples $(\alpha=5 \%)$. The prevalence of self-perceived need for dental treatment was $88.6 \%$. The presence of dental caries (OR = 2.10; IC 95\%: 1.22-3.61), tooth loss (OR = 15.81; IC 95\%: 2.14-116.56), dental pain in the last six months $(\mathrm{OR}=1.87$; IC 95\%: 1.06-3.31), and enmeshed family cohesion type (OR = 10.23; IC 95\%: 3.96-26.4) remained associated with the self-perceived need for dental treatment in the final model. In conclusion, dental caries, dental pain, tooth loss, and family cohesion influenced the self-perceived need for dental treatment in adolescents.
\end{abstract}

\section{Introduction}

Self-perceived need for dental treatment is a subjective measure that depends on how people assess their oral health condition [1-3] and may influence the search for dental services [4], acting as an important predictor of dental care utilization [5]. Studies on the self-perceived need for dental treatment have been conducted mainly in adults and the elderly $[2,6,7]$; however, adolescence is considered a strategic period for such studies due to the large number of changes that occur in this phase and because oral habits formed in adolescence may persist later in adulthood $[8$, 9]. Also, oral hygiene practices are often neglected during adolescence and this group is exposed to risk factors for oral diseases such as unbalanced sugar intake and a low fre- quency of dental visits [10-12]. Moreover, a previous study conducted in Brazil among adolescents demonstrated that the self-perceived need for dental treatment was the main reason for dental visits for this age group [13].

The knowledge regarding the factors associated with the self-perceived need for dental treatment in adolescents can assist the planning of education, prevention, and health promotion programs for this target population. Previous studies have shown that aspects such as lower quality of life related to oral health, sociodemographic factors, searching dental services for treatment, dental pain, dissatisfaction with teeth and mouth, and dental caries were associated with the selfperceived need for dental treatment in adolescents [3, 14]. Another factor that has been associated with oral health outcomes in adolescents is oral health literacy $(\mathrm{OHL})[15,16]$, 
which is the ability to identify, understand. and apply oral health information and influences health decision-making $[17,18]$. Thus, it is important to evaluate the influence of this social determinant of health on the self-perceived need for dental treatment given that there is no previous study conducted in this perspective.

Adolescents are commonly dependent on family members, hence are influenced by the family environment [19, 20]. Therefore, another important aspect that should be considered during adolescence is related to the family environment. Family cohesion is a component of family functioning and assesses the level of proximity among family members [21]. A previous study showed that higher levels of family cohesion can positively contribute to adequate health behaviors in adolescence [22], with low levels of family cohesion contributing to lower life satisfaction in adolescents [23], probably reducing motivation and interest in issues related to oral health. A growing number of cross-sectional studies have examined the association between low family cohesion and dental problems such as dental caries in adolescents [16, 24] but the role of family cohesion in adolescents' selfperceived need for dental treatment has not been explored. This information is important because adolescents are influenced by the family environment to make decisions, as well as establish financial, psychological, and emotional dependence with guardians and parents $[20,25,26]$.

The conceptual hypothesis of this study was that a higher level of family cohesion influences the prevalence of self-perceived need for dental treatment in adolescents; thus, this study assessed the association between family cohesion and self-perceived need for dental treatment in adolescents aged 15 to 19 .

\section{Materials and Methods}

2.1. Ethical Issues. This study was approved by the Human Research Ethics Committee of the State University of Paraiba (certificate number: 55953516.2.1001.5187) and followed the guidelines established by the Declaration of Helsinki. Parents/caregivers signed an informed consent form, and adolescents signed a statement of informed consent authorizing their participation in the research.

2.2. Study Design and Sample Selection. An analytical, crosssectional, school-based study was conducted with adolescents aged 15 to 19 years enrolled in public and private schools in a city in Campina Grande, Brazil. Data was collected between October 2016 and July 2017. Students undergoing orthodontic treatment, with learning problems, neurological disorders and/or physical disabilities, or in need of specialized support were excluded from the study. Probabilistic sampling by clusters was conducted in two stages. In the first stage, 16 public schools and 16 private schools were randomly selected in the city's six administrative districts. In the second stage, students were selected by simple random sampling in each school.

The sample calculation was performed for analytical comparative studies between two independent proportions using Software G* Power version 3.1 (Franz Faul, Universitat
Kiel, Germany) adopting a significance level of $95 \%$ and power of $80 \%$. The proportion estimates of the pilot study indicated a prevalence of self-perceived need for dental treatment in individuals from disconnected and bonded families of $76.4 \%$ and $87.5 \%$, respectively. The minimum sample calculated was 376 , to which a design effect of 1.6 was applied, reaching a sample of 602 . To this number, $20 \%$ was added to compensate for possible losses, reaching a final sample of 753 participants.

2.3. Training and Calibration Exercises. Two dentists were trained to diagnose dental caries using the criteria proposed by Nyvad and Baelum [27] by an expert in the field of diagnosis and epidemiology and took place in two stages according to the method proposed by Peres et al. [28]. The first theoretical stage involved the study of the diagnostic criteria through the projection of images of the conditions that could be observed in the clinical examination, clinical records, and the steps to follow in the clinical examination. In the practical stage, gold standard clinical examinations were conducted by the examiners of fifty adolescents aged 15 to 19 years old from a public school. The students were reexamined after an interval of seven days to determine the interexaminer (kappa $=0.89$ to 0.90$)$ and intraexaminer (kappa $=0.88$ to 0.90$)$ agreement. Adolescents examined in the calibration exercise were not included in the main study.

Two interviewers were trained and calibrated to apply the Brazilian version of the Rapid Estimate of Adult Literacy in Dentistry (BREALD-30) following the methodology of Vilella et al. [29]. A researcher considered the gold standard in OHL, and BREALD-30 was responsible for this step. Theoretical training was first carried out on the application criteria of the instrument; then, practical training and calibration were performed using a bank of 15 videos of individuals with different levels of OHL. The agreement between the two examiners was 0.870 . and the intraexaminer agreement was 0.898 and 0.871 . Kappa coefficients between examiners and the gold standard were 0.889 and 0.884 .

2.4. Pilot Study. To test and evaluate the proposed methodology, a pilot study was conducted with fifty adolescents aged 15 to 19 years randomly selected from a private school $(n=25)$ and a public school $(n=25)$ and was not included in the main sample. The results of this stage did not reveal the need for changes to the study methodology.

2.5. Nonclinical Data Collection. The parents/caregivers completed a sociodemographic questionnaire collecting information about the adolescent's sex, self-declared color, and maternal education. To determine the social class of the adolescents, the Brazil Economic Classification Criterion proposed by the Brazilian Association of Research Companies was used, which considers the education of the head of the family, the number of consumer goods reported by parents/guardians, and access to public services [30]. Scores were attributed to each item, and the total sum allows families to be classified in decreasing order of economic favoring in classes A, B1, B2, C1, C2, D, and E. For the present study, the social class was dichotomized upwards (classes A and B) 
or low (classes C, D, and E) [21]. The adolescents were required to complete a questionnaire on Access and Use of Health Services of the National Oral Health Survey to assess the self-perception of the need for treatment and self-report of dental pain in the last six months [31].

The Family Adaptability and Cohesion Evaluation Scales (FACES III) is validated for use in Brazil and was completed by adolescents to assess levels of family cohesion and adaptability. FACES III contains 20 questions, 10 even number questions related to family cohesion, and 10 odd questions address family adaptability. According to the family cohesion scores, families were classified into four groups: enmeshed (high degree of dependency among family members), connected (moderate degree of independence between family members), separated (considerable degree of independence between family members), and disengaged (very high degree of independence among family members). The level of family adaptability was classified as very flexible/chaotic (very high family adaptability), flexible (moderate to high family adaptability), structured (low to moderate family adaptability), and rigid (very low family adaptability) [32].

BREALD-30 was applied to measure the functional OHL of adolescents, which was validated for use with this population [33]. This instrument contains thirty words related to dentistry following an increasing order of reading difficulty. The students read the words out loud to the examiner, and a point is given for each word pronounced correctly and zero for incorrect pronunciation; thus, higher scores denote a higher level of OHL. The total BREALD-30 score was categorized into inadequate, marginal, or adequate literacy based on the distribution of scores, 0-18, 19-22, and 23-30, respectively, using sample distribution tertiles as cutoff points.

2.6. Clinical Data Collection. Prior to the clinical examination, the adolescents underwent supervised brushing and topical application of fluoride. In a private room at the school, students were examined individually, sitting in a school chair in front of the examiner. The participants' teeth were evaluated with the aid of a headlight (Petzl Zoom headlamp, Petzl America, Clearfield, UT, USA), mouth mirror (PRISMA ${ }^{\circledR}$, São Paulo, SP, Brazil), and previously sterilized WHO periodontal probe (GOLGRAN ${ }^{\circledR}$, São Paulo, SP, Brazil). To dry the dental surfaces before the clinical examination, sterile gases were used, as well as relative insulation with a cotton roll to keep the teeth dry. The biosafety protocols were followed by the examiners who used the necessary personal protective equipment.

Dental caries was diagnosed using the Nyvad Classification [27] based on visual and tactile findings and allows to detect the activity and severity of injuries. In the present study, the codes considered to demonstrate the presence of caries were 2 (active caries with a discontinuous surface), 3 (active caries with cavitation), 5 (inactive caries with a discontinued surface), and 6 (inactive caries with cavitation). Tooth loss due to caries was assessed during the oral clinical examination.
2.7. Statistical Approach. Descriptive analysis was performed, followed by unadjusted and adjusted analyzes. The dependent variable was the self-perceived need for treatment (yes and no), and the independent variables were sociodemographic characteristics, OHL, dental caries, presence of toothache in the last 6 months, and loss of permanent teeth due to caries, family cohesion, and family adaptability. Associations between independent variables and self-perceived need for treatment were tested by robust logistic regression for complex samples. Variables with a $p$ value $<0.20$ in the unadjusted analysis were incorporated into the adjusted analysis, and those with a $p$ value $<0.05$ after the adjustments were considered significantly associated with the outcome. Data organization and statistical analysis were performed using the SPSS (SPSS for Windows, version 22.0; IBM Inc., Armonk, NY, USA).

\section{Results}

Seven hundred and forty-six adolescents aged 15 to 19 years participated in the study. The losses of seven students occurred due to their absence on two consecutive days after the exams. The prevalence of adolescents who perceived the need for treatment was $88.6 \%$. Table 1 presents the subjects' demographic characteristics, showing that most adolescents were female and $71.7 \%$ declared themselves to be nonWhite and low social class $(57.4 \%)$, and mothers had 8 or more years of schooling (59.7\%). More than a third of the adolescents had a marginal level of OHL (37.5\%). Family cohesion of the disengaged type (46.1\%) and family adaptability of the flexible type $(32.8 \%)$ were most common.

In the adjusted analysis (Table 2), the variables that remained associated with the self-perceived need for dental treatment were the presence of dental caries $(\mathrm{OR}=2.10$; 95\% CI: $1.22-3.61)$, loss of permanent teeth due to caries $(\mathrm{OR}=15.81 ; 95 \% \mathrm{CI}: 2.14-116.56)$, the presence of toothache in the last 6 months $(\mathrm{OR}=1.87 ; 95 \% \mathrm{CI}: 1.06-3.31)$, and family cohesion of the agglutinated type $(\mathrm{OR}=10.23$; 95\% CI: 3.96-26.4).

\section{Discussion}

The conceptual hypothesis of this study was confirmed that adolescents from enmeshed families and those with dental caries, tooth pain, and tooth loss demonstrated a higher prevalence of self-perceived need for dental treatment compared to those who did not present these conditions. The prevalence of self-perceived need for dental treatment in this study was high $(88.6 \%)$, higher than that reported $(62.6 \%)$ in a previous study conducted with Brazilian adolescents from the southeast region [14]. These differences may be related to regional and socioeconomic discrepancies in Brazil as this study was conducted in a city located in the northeast, a region that exhibits a higher prevalence of oral health problems compared to the southeast [31].

Dental caries was associated with the self-perceived need for dental treatment in adolescents, in line with studies conducted in Brazilian adolescents aged 15-19 [14, 34]. Adolescents from Thailand aged 12-15 who had a higher number 
Table 1: Descriptive statistics of 15-19-year-old adolescents.

\begin{tabular}{|c|c|}
\hline Variable & $N(\%)$ \\
\hline \multicolumn{2}{|l|}{ Adolescent sex } \\
\hline Female & $444(59.5)$ \\
\hline Male & $302(40.5)$ \\
\hline \multicolumn{2}{|l|}{ Self-declared color } \\
\hline White & $211(28.3)$ \\
\hline Non-White & $535(71.7)$ \\
\hline \multicolumn{2}{|l|}{ Social class } \\
\hline C-D-E & $428(57.4)$ \\
\hline$A-B$ & $318(42.6)$ \\
\hline \multicolumn{2}{|l|}{ Mother's schooling } \\
\hline$\geq 8$ years of study & $443(59.7)$ \\
\hline$<8$ years of study & $299(40.3)$ \\
\hline \multicolumn{2}{|l|}{ Oral health literacy } \\
\hline Inadequate & $247(33.1)$ \\
\hline Marginal & $280(37.5)$ \\
\hline Adequate & $219(29.4)$ \\
\hline \multicolumn{2}{|l|}{ Dental caries } \\
\hline Present & $354(47.5)$ \\
\hline Absent & $392(52.5)$ \\
\hline \multicolumn{2}{|l|}{ Loss of permanent teeth } \\
\hline Yes & $130(17.4)$ \\
\hline No & $616(82.6)$ \\
\hline \multicolumn{2}{|c|}{ Presence of toothache in the last 6 months } \\
\hline Yes & $281(38.1)$ \\
\hline No & $456(61.9)$ \\
\hline \multicolumn{2}{|l|}{ Family cohesion } \\
\hline Enmeshed & $15(2.0)$ \\
\hline Connected & $121(16.2)$ \\
\hline Separated & $266(35.7)$ \\
\hline Disengaged & $344(46.1)$ \\
\hline \multicolumn{2}{|l|}{ Family adaptability } \\
\hline Very flexible/chaotic & $163(21.9)$ \\
\hline Flexible & $244(32.8)$ \\
\hline Structured & $216(29.0)$ \\
\hline Rigid & $122(16.4)$ \\
\hline \multicolumn{2}{|c|}{ Self-perceived need for dental treatment } \\
\hline Yes & $597(88.6)$ \\
\hline No & $77(11.4)$ \\
\hline
\end{tabular}

of untreated dental caries also demonstrated an increased chance to perceive the need for dental care [3]. Dental caries remains a global public health problem and are associated with a poor quality of life related to oral health and may restrict adolescents from daily normal activities [8, 35]. Therefore, dental caries influence oral health selfperception in adolescence [36], probably because this population has increased interest in the aesthetic [37] aspect to maintain social relationships [11]. This finding is important because untreated dental caries can lead to pain and tooth loss [38]; thus, general society, dentists, and policymakers should implement preventive measures and early treatment for dental caries.

Another condition associated with the self-perceived need for dental treatment was dental pain in the last 6 months. Dental pain is a serious public health problem [39] and is associated with a poorer quality of life [40], oral health dissatisfaction [41], sleep disorders, and limitations to daily school activities among adolescents [1]. It may also lead to discomfort which may influence the self-perceived need for dental treatment. In this sense, a previous study conducted in Brazil with adolescents aged 15-19 demonstrated that dental pain at any time in life was associated with a higher prevalence of dental visits [13], indicating a symptomatic pattern for seeking dental services among adolescents [14]. This could be avoided through oral health education regimens to stimulate preventive dental appointments in addition to dental visits only due to clinical symptoms.

Tooth loss due to untreated dental caries was associated with the self-perceived need for dental treatment, suggesting that tooth loss negatively impacts adolescents' quality of life [35] and impairs basic functions such as chewing, speaking, and self-confidence [42]. Thus, tooth loss may influence the self-perceived need for dental treatment in this population. Although this problem is largely preventable by adequate oral health practices $[43,44]$, the prevalence of tooth loss increases with aging [45]; therefore, adolescence is a critical period to strengthen preventive measures and implement adequate oral health behaviors contributing to maintaining a better oral health status later in life.

Regarding family cohesion, adolescents who were from enmeshed families (high level of family cohesion) had an increased self-perceived need for dental treatment. A previous study conducted in Brazil showed that adolescents aged 12 who had high family cohesion went to dental visits more frequently [21]. Furthermore, other studies of adolescents revealed that a low level of family cohesion was associated with untreated dental caries [16, 24]. Therefore, adolescents from families less connected may present worse oral health behaviors [22]. Although the 15 to 19 age group has greater autonomy compared to younger children [46], a higher level of family cohesion probably indicates greater family support and attention given to the adolescent's oral health $[19,22]$. Adolescents who grow up in a cohesive family likely have greater discernment to perceive changes in oral health affecting the self-perceived need for dental treatment, suggesting the importance of valuing family cohesion for the establishment of critical attitudes and oral self-care by adolescents.

OHL was not associated with the self-perceived need for dental treatment. The inclusion of clinical variables and mediators in the model may have hidden this association. Moreover, it is important to clarify that this study included only a functional health literacy measure. BREALD-30 is considered a screening tool and may not have been sensitive enough in these circumstances; however, it is the only validated tool available to date to assess OHL in Brazilian adolescents [33].

A limitation of this study is its cross-sectional design, which does not allow establishing a causal relationship between exposure and outcome. However, methodological 
TABLE 2: Nonadjusted and adjusted robust binary logistic regression for the association between family cohesion and self-perceived need for dental treatment among adolescents.

\begin{tabular}{|c|c|c|c|c|c|c|}
\hline \multirow[b]{2}{*}{ Variable } & \multicolumn{6}{|c|}{ Self-perceived need for dental treatment } \\
\hline & $\begin{array}{c}\text { Yes } \\
n(\%)\end{array}$ & $\begin{array}{c}\text { No } \\
n(\%)\end{array}$ & $p$ value & Nonadjusted OR (95\% CI) & $p$ value & Adjusted OR (95\% CI) \\
\hline \multicolumn{7}{|l|}{ Adolescent sex } \\
\hline Female & $363(90.3)$ & $39(9.7)$ & 0.08 & $1.44(0.94-2.19)$ & - & - \\
\hline Male & $234(86.0)$ & $38(14.0)$ & - & 1.00 & - & - \\
\hline \multicolumn{7}{|l|}{ Self-declared color } \\
\hline White & $165(88.7)$ & $432(11.3)$ & - & - & - & - \\
\hline Non-White & $432(88.5)$ & $56(11.5)$ & - & - & - & - \\
\hline \multicolumn{7}{|l|}{ Social class } \\
\hline C-D-E & $359(91.1)$ & $35(8.9)$ & 0.03 & $1.84(1.03-3.28)$ & - & - \\
\hline$A-B$ & $238(85.0)$ & $42(15.0)$ & - & 1.00 & - & - \\
\hline \multicolumn{7}{|l|}{ Mother's schooling } \\
\hline$\geq 8$ years of study & $345(88.0)$ & $47(12.0)$ & - & - & - & - \\
\hline$<8$ years of study & $250(89.6)$ & $29(10.4)$ & - & - & - & - \\
\hline \multicolumn{7}{|l|}{ Oral health literacy } \\
\hline Inadequate & $207(88.1)$ & $28(11.9)$ & - & - & - & - \\
\hline Marginal & $230(90.6)$ & $24(9.4)$ & - & - & - & - \\
\hline Adequate & $160(86.5)$ & $25(13.5)$ & - & - & - & - \\
\hline \multicolumn{7}{|l|}{ Dental caries } \\
\hline Present & $316(93.8)$ & $21(6.2)$ & $<0.001$ & $2.99(1.77-5.07)$ & 0.007 & $2.10(1.22-3.61)$ \\
\hline Absent & $281(83.4)$ & $56(16.6)$ & - & 1.00 & - & 1.00 \\
\hline \multicolumn{7}{|l|}{ Loss of permanent teeth } \\
\hline Yes & $124(99.2)$ & $1(0.8)$ & 0.003 & $20.2(2.79-147-18)$ & 0.007 & $15.81(2.14-116.56)$ \\
\hline No & $473(86.2)$ & $76(13.8)$ & - & 1.00 & - & 1.00 \\
\hline \multicolumn{7}{|c|}{ Presence of toothache in the last 6 months } \\
\hline Yes & $249(93.3)$ & $18(6.7)$ & 0.002 & $2.18(1.32-3.62)$ & 0.030 & $1.87(1.06-3.31)$ \\
\hline No & $341(85.3)$ & $59(15.8)$ & - & 1.00 & - & 1.00 \\
\hline \multicolumn{7}{|l|}{ Family cohesion } \\
\hline Enmeshed & $13(100.0)$ & $0(0.0)$ & $<0.001$ & $7.66(1.61-36.34)$ & $<0.001$ & $10.23(3.96-26.4)$ \\
\hline Connected & $94(89.4)$ & $11(10.5)$ & - & - & - & - \\
\hline Separated & $208(86.3)$ & $33(13.7)$ & - & - & - & - \\
\hline Disengaged & $282(89.5)$ & $33(10.5)$ & - & 1.00 & - & 1.00 \\
\hline \multicolumn{7}{|l|}{ Family adaptability } \\
\hline Very flexible/chaotic & $139(93.3)$ & $10(6.7)$ & - & - & - & - \\
\hline Flexible & $191(86.1)$ & $31(13.9)$ & 0.04 & $0.45(0.21-0.97)$ & - & - \\
\hline Structured & $171(86.4)$ & $27(13.6)$ & 0.03 & $0.44(0.21-0.93)$ & - & - \\
\hline Rigid & $95(91.3)$ & $9(8.7)$ & - & 1.00 & - & - \\
\hline
\end{tabular}

procedures were designed to reduce possible bias and increase the internal and external validity of the findings, for example, steps such as sample size calculation, a pilot study, examiners' training, and the use of validated instruments for adolescents were followed. Moreover, epidemiological studies contribute to advances in the field and subside public health policies.

The results of the present study are important to guide oral health education programs in adolescence. The objectives of the Health at School Program (HSP) can be restructured to encourage adolescents' self-criticism in identifying oral health changes early and seeking dental services. Health at School Program is a strategy to promote general and oral health in Brazilian schools. In addition, including the assessment of the family environment is of great relevance in the expansion of healthy behaviors in adolescents. Dental professionals must improve their approach and intervention for adolescents by integrating subjective information into clinical assessments.

\section{Conclusions}

The presence of dental caries, toothache reported in the last 6 months, tooth loss, and family cohesion of the agglutinated 
type influenced the self-perception of the need for dental treatment in adolescents aged 15 to 19 years.

\section{Data Availability}

The data used to support the findings of this study are available from the corresponding author upon request.

\section{Conflicts of Interest}

The authors declare that they have no conflicts of interest.

\section{Acknowledgments}

This study was financed in part by the Coordenação de Aperfeiçoamento de Pessoal de Nível Superior-Brasil (CAPES) [grant number 001] and the Fundação de Apoio à Pesquisa do Estado da Paraíba.

\section{References}

[1] K. O. Mashoto, A. N. Åstrøm, J. David, and J. R. Masalu, “Dental pain, oral impacts and perceived need for dental treatment in Tanzanian school students: a cross-sectional study," Health and Quality of Life Outcomes, vol. 7, no. 1, p. 73, 2009.

[2] A. M. E. B. Martins, S. M. Barreto, and I. A. Pordeus, "Factors associated to self perceived need of dental care among Brazilian elderly," Revista de Saúde Pública, vol. 42, no. 3, pp. 487496, 2008.

[3] S. Krisdapong, P. Prasertsom, K. Rattanarangsima, and A. Sheiham, "Associations between perceived needs for dental treatment, oral health-related quality of life and oral diseases in school-aged Thai children," Community Dentistry and Oral Epidemiology, vol. 42, no. 4, pp. 323-332, 2014.

[4] S. Schützhold, B. Holtfreter, U. Schiffner, T. Hoffmann, T. Kocher, and W. Micheelis, "Clinical factors and selfperceived oral health," European Journal of Oral Sciences, vol. 122, no. 2, pp. 134-141, 2014.

[5] Z. Marshman, J. Porritt, T. Dyer, C. Wyborn, J. Godson, and S. Baker, "What influences the use of dental services by adults in the UK?," Community Dentistry and Oral Epidemiology, vol. 40, no. 4, pp. 306-314, 2012.

[6] N. Lundegren, "Oral health and self-perceived oral treatment need of adults in Sweden," Swedish Dental Journal, vol. 223, pp. 10-76, 2012.

[7] C. E. Dalazen, R. A. Bomfim, and A. D. De-Carli, "Factors behind self-perceived need for dental treatment and prosthesis in Brazilian elderly people," Ciência \& Saúde Coletiva, vol. 23, no. 3, pp. 945-952, 2018.

[8] C. S. Sfreddo, C. H. C. Moreira, B. Nicolau, F. R. Ortiz, and T. M. Ardenghi, "Socioeconomic inequalities in oral healthrelated quality of life in adolescents: a cohort study," Quality of Life Research, vol. 28, no. 9, pp. 2491-2500, 2019.

[9] A. C. Gomes, M. A. B. Rebelo, A. C. de Queiroz et al., "Socioeconomic status, social support, oral health beliefs, psychosocial factors, health behaviours and health-related quality of life in adolescents," Quality of Life Research, vol. 29, no. 1, pp. 141-151, 2020.

[10] K. K. Mak and J. R. Day, "Dental health behaviours among early adolescents in Hong Kong," International Journal of Dental Hygiene, vol. 9, no. 2, pp. 122-126, 2011.
[11] F. D. Vazquez, K. L. Cortellazzi, C. D. Gonçalo et al., "Qualitative study on adolescents' reasons to non-adherence to dental treatment," Ciência \& Saúde Coletiva, vol. 20, no. 7, pp. 2147-2156, 2015.

[12] M. A. Peres, A. Sheiham, P. Liu et al., "Sugar consumption and changes in dental caries from childhood to adolescence," Journal of Dental Research, vol. 95, no. 4, pp. 388-394, 2016.

[13] A. C. Massoni, É. Porto, L. R. Ferreira et al., "Access to oral healthcare services of adolescents of a large-size municipality in northeastern Brazil," Brazilian Oral Research, vol. 34, article e029, 2020.

[14] I. P. da Cunha, F. L. Mialhe, A. C. Pereira et al., "Self-perceived dental treatment need among adolescents: A hierarchical analysis," Community Dentistry and Oral Epidemiology, vol. 48, no. 2, pp. 130-136, 2020.

[15] L. C. Dutra, L. C. M. de Lima, É. T. B. Neves et al., “Adolescents with worse levels of oral health literacy have more cavitated carious lesions," PloS One, vol. 14, no. 11, article e0225176, 2019.

[16] É. T. B. Neves, L. C. Dutra, M. C. Gomes et al., “The impact of oral health literacy and family cohesion on dental caries in early adolescence," Community Dentistry and Oral Epidemiology, vol. 48, no. 3, pp. 232-239, 2020.

[17] J. Y. Lee, K. Divaris, A. D. Baker, R. G. Rozier, and J. R. Vann, "The relationship of oral health literacy and self-efficacy with oral health status and dental neglect," American Journal of Public Health, vol. 102, no. 5, pp. 923-929, 2012.

[18] R. T. Firmino, F. M. Ferreira, S. M. Paiva, A. F. Granville-Garcia, F. C. Fraiz, and C. C. Martins, "Oral health literacy and associated oral conditions: A systematic review," The Journal of the American Dental Association, vol. 148, no. 8, pp. 604613, 2017.

[19] Y. S. Kingon and A. L. O'sullivan, "The family as a protective asset in adolescent development," Journal of Holistic Hursing, vol. 19, no. 2, pp. 102-121, 2001.

[20] E. M. M. Pratta and M. A. Santos, "Família e adolescência: a influência do contexto familiar no desenvolvimento psicológico de seus membros," Psicologia em Estudo, vol. 12, no. 2, pp. 247-256, 2007.

[21] É. T. B. Neves, L. C. M. Lima, L. C. Dutra et al., "Oral health literacy, sociodemographic, family, and clinical predictors of dental visits among Brazilian early adolescents," International Journal of Paediatric Dentistry, vol. 31, no. 2, pp. 204-211, 2021.

[22] L. L. Ferreira, G. A. M. Brandão, G. Garcia et al., "Family cohesion associated with oral health, socioeconomic factors and health behavior," Ciência \& Saúde Coletiva, vol. 18, no. 8, pp. 2461-2473, 2013.

[23] W.-H. Lin and C.-C. Yi, "The effect of family cohesion and life satisfaction during adolescence on later adolescent outcomes: A prospective study," Youth \& Society, vol. 51, no. 5, pp. $680-706,2019$.

[24] L. C. Dutra, É. T. B. Neves, L. C. M. . Lima et al., "Degree of family cohesion and social class are associated with the number of cavitated dental caries in adolescents," Brazilian Oral Research, vol. 34, article e037, 2020.

[25] B. T. Reeb, S. Y. Chan, K. J. Conger et al., "Prospective effects of family cohesion on alcohol-related problems in adolescence: similarities and differences by race/ethnicity," Journal of Youth and Adolescence, vol. 44, no. 10, pp. 1941-1953, 2015. 
[26] S. Plenty and C. Mood, "Money, peers and parents: social and economic aspects of inequality in youth wellbeing," Journal of Youth and Adolescence, vol. 45, no. 7, pp. 1294-1308, 2016.

[27] B. Nyvad and V. Baelum, "Nyvad criteria for caries lesion activity and severity assessment: a validated approach for clinical management and research," Caries Research, vol. 52, no. 5, pp. 397-405, 2018.

[28] M. A. Peres, J. Traebert, and W. Marcenes, "Calibration of examiners for dental caries epidemiologic studies," Cadernos de Saúde Pública, vol. 17, no. 1, pp. 153-159, 2001.

[29] K. D. Vilella, L. R. S. Assunção, M. C. Junkes, J. V. Menezes, F. C. Fraiz, and M. Ferreira Fde, "Training and calibration of interviewers for oral health literacy using the BREALD-30 in epidemiological studies," Brazilian Oral Research, vol. 30, no. 1, p. e90, 2016.

[30] Brazilian Market Research Association-ABEP, "Brazilian Criteria 2015 and social class distribution update for 2016," 2016, 2021, http://www.abep.org/criterio-brasil.

[31] Brasil, "Ministério da Saúde. Secretaria de Atenção à Saúde," in Secretaria de Vigilância em Saúde. SB Brasil 2010, vol. 2012, Pesquisa Nacional de Saúde Bucal: resultados principais, Brasília.

[32] O. G. Falceto, E. D. Busnello, M. C. Bozzetti, O. G. Falceto, E. D. Busnello, and M. C. Bozzetti, "Validation of diagnostic scales of Family functioning for use in primary health care services," Revista Panamericana de Salud Publica= Pan American Journal of Public Health, vol. 7, no. 4, pp. 255-263, 2000.

[33] L. C. M. Lima, E. T. B. Neves, L. C. Dutra et al., "Psychometric properties of BREALD-30 for assessing adolescents' oral health literacy," Revista de Saude Publica, vol. 53, no. 53, p. 53, 2019.

[34] M. C. Lopes, P. R. Silva, M. G. H. Biazevic, M. A. B. Rebelo, and E. M. Crosato, "Necessidade de Tratamento Decorrente da Cárie Dentária em Estudantes de 15 a 19 Anos de Idade, em Manaus-AM, Brasil e fatores associados," Pesquisa Brasileira em Odontopediatria e Clínica Integrada, vol. 12, no. 1, pp. 83-88, 2012.

[35] C. A. Feldens, T. M. Ardenghi, A. I. Dos Santos Dullius, F. Vargas-Ferreira, P. A. G. Hernandez, and P. F. Kramer, "Clarifying the impact of untreated and treated dental caries on oral health-related quality of life among adolescents," Caries Research, vol. 50, no. 4, pp. 414-421, 2016.

[36] M. P. Silva, M. V. Vettore, M. A. B. Rebelo et al., "Clinical consequences of untreated dental caries, individual characteristics, and environmental factors on self-reported oral health measures in adolescents: a follow-up prevalence study," Caries Research, vol. 54, no. 2, pp. 176-184, 2020.

[37] G. F. Boeira, M. M. S. Salas, D. C. Araújo, A. S. Masotti, M. B. Correa, and F. F. Demarco, "Factors influencing dental appearance satisfaction in adolescents: a cross-sectional study conducted in southern Brazil," Brazilian Journal of Oral Sciences, vol. 15, no. 1, pp. 8-15, 2016.

[38] S. M. Costa, M. H. N. G. Abreu, M. Vasconcelos, R. . C. G. S. Lima, M. Verdi, and E. F. . Ferreira, "Desigualdades na distribuição da cárie dentária no Brasil: uma abordagem bioética," Ciência \& Saúde Coletiva, vol. 18, no. 2, pp. 461-470, 2013.

[39] A. C. L. T. Massoni, É. Porto, L. R. B. O. Ferreira, M. . N. C. Gomes, A. F. Granville-Garcia, and S. D’Avila, “Tooth pain and associated factors among adolescents of a large population municipality in northeastern Brazil," Ciência \& Saúde Coletiva, vol. 25, no. 2, pp. 673-682, 2020.
[40] R. C. L. da Fonseca, J. L. F. Antunes, A. M. Cascaes, and R. A. Bomfim, "Analysis of the combined risk of oral problems in the oral health-related quality of life of Brazilian adolescents: multilevel approach," Clinical Oral Investigations, vol. 24, no. 2, pp. 857-866, 2020.

[41] A. G. Reboucas, A. M. Cavalli, L. Zanin, G. M. B. Ambrosano, and F. M. Flório, "Factors associated with Brazilian adolescents' satisfaction with oral health," Community Dental Health, vol. 35, no. 2, pp. 95-101, 2018.

[42] P. Kaur, S. Singh, A. Mathur et al., "Impact of dental disorders and its influence on self esteem levels among adolescents," Journal of Clinical and Diagnostic Research: JCDR, vol. 11, no. 4, pp. 5-8, 2017.

[43] P. R. Barbato and M. A. Peres, "Tooth loss and associated factors in adolescents: a Brazilian population-based oral health survey," Revista de Saúde Pública, vol. 43, no. 1, pp. 13-25, 2009.

[44] M. Saito, Y. Shimazaki, K. Fukai et al., "A multilevel analysis of the importance of oral health instructions for preventing tooth loss: The 8020 Promotion Foundation Study of Japanese Dental Patients," BMC Oral Health, vol. 20, no. 1, p. 328, 2020.

[45] N. J. Kassebaum, E. Bernabé, M. Dahiya, B. Bhandari, C. J. L. Murray, and W. Marcenes, "Global burden of severe tooth loss: a systematic review and meta-analysis," Journal of Dental Research, vol. 93, Supplement 7, pp. 20S-28S, 2014.

[46] G. C. Patton, S. M. Sawyer, J. S. Santelli et al., "Our future: a _Lancet_commission on adolescent health and wellbeing," The Lancet, vol. 387, no. 10036, pp. 2423-2478, 2016. 